\title{
IDENTIFICAÇÃO E ANÁLISE DA CADEIA DE DISTRIBUIÇÃO DAS FRUTAS CÍTRICAS DE MESA SEM SEMENTES: UM ESTUDO DE CASO NA CIDADE DE SÃO PAULO ${ }^{1}$
}

\author{
ANA JÚLIA TEIXEIRA SENNA², EUGENIO ÁVILA PEDROZO ${ }^{3}$, OTTO CARLOS KOLLER ${ }^{4}$
}

RESUMO - O objetivo deste trabalho foi identificar mecanismos de comercialização para as frutas cítricas, de mesa, sem sementes, provenientes dos municípios de São Gabriel, Santa Margarida do Sul e Rosário do Sul, situados no limite norte da metade sul do Estado do Rio Grande do Sul. O método de pesquisa foi um estudo de caso, de caráter exploratório, em que foram entrevistados dez comerciantes na cidade de São Paulo. Constatou-se que há comerciantes que importam frutas cítricas do Uruguai e da Espanha para abastecer o mercado interno e que esses, em sua maioria, estão interessados em substituir as importações por frutas produzidas no Brasil, desde que possuam qualidade semelhante à das frutas importadas e preço mais baixo. A Central de Abastecimento (CEAGESP) é o estabelecimento que, num mesmo lugar, responde pelo maior volume de frutas distribuídas. Neste estudo, determinou-se a configuração da cadeia de distribuição das frutas cítricas sem sementes.

Termos para Indexação: canais de distribuição, comercialização, laranjas e tangerinas.

\section{IDENTIFICATION AND ANALISYS OF THE DISTRIBUTION CHAIN OF THE SEEDLESS CITRIC FRUITS: A CASE STUDY IN SÃO PAULO CITY}

\begin{abstract}
This research aims at identifying commercial mechanisms for in nature seedless citric fruits which are produced in São Gabriel, Santa Margarida do Sul and Rosário do Sul, cities located in the north boundary of the southern half of the state of Rio Grande do Sul. The research method consisted of an exploratory case study, in which ten traders were interviewed in São Paulo city. It has been noticed that in São Paulo there are traders who import citric fruit from Uruguay and Spain in order to supply the domestic market, and most of them would like to replace such imports for fruits produced in Brazil as long as similar quality and lower prices can be achieved. The CEAGESP (Food Supply Distribution Center) is the establishment that, in a single place, accounts for the highest volume of fruit distribution. In this study the configuration of the distribution chain of seedless citric fruits was set up.
\end{abstract}

Index Terms: distribution channels, trading, oranges and tangerines.

\section{INTRODUÇÃO}

As frutas cítricas, compreendidas principalmente por laranjas, tangerinas, limões, limas e pomelos, desempenham um papel importante na alimentação humana, principalmente sob a forma de fruta fresca e suco.

O mercado interno de frutas cítricas in natura, conforme Boteon (2000), apresenta uma característica particular se comparado a outros países tradicionais em comercialização de fruta fresca, como os Estados Unidos e a Espanha. O consumidor brasileiro compra tanto frutos da mesma espécie para consumo, como fruta de mesa, quanto cultivares (ou variedades) próprias para a produção de suco. A disponibilidade dessas últimas no mercado é muito maior que as cultivares de mesa, fato que está diretamente relacionado com a influência da indústria de suco no País. Assim, atualmente, há uma tendência de especialização do mercado de frutas de mesa que contemple as exigências dos consumidores.

A metade sul do Estado do Rio Grande do Sul (RS) caracteriza-se, principalmente, pela atividade primária, baseada na pecuária, com grandes rebanhos bovinos, ovinos e eqüinos, enquanto, na agricultura, destacam-se as culturas de arroz e soja. Mesmo com a abertura dos mercados mundiais, a rentabilidade rural (ou agrícola) dessas atividades tem sido substancialmente reduzida, uma vez que muitos de seus produtos (e subprodutos)

${ }^{1}$ (Trabalho 112-06). Recebido em : 03-08-2006. Aceito para publicação em : 06-07-2007.

${ }^{2}$ Engenheira Agrícola, Mestre em Agronegócios, Doutoranda em Agronegócios na Universidade Federal do Rio Grande do Sul - UFRGS. Centro de Estudos e Pesquisas em Agronegócios (CEPAN). Programa de Pós-Graduação em Agronegócios- PPG-Agronegócios. Av. Whashinghton Luís, 855. Tel: 33083864. E-mail: anajuju@terra.com.br

${ }^{3}$ Professor do PPG-Agronegócios e PPGA/Escola de Administração/Universidade Federal do Rio Grande do Sul. Centro de Estudos e Pesquisas em Agronegócios (CEPAN). Av. Whashinghton Luís, 855. Tel: 33083864. E-mail: eapedrozo@adm.ufrgs.br

${ }^{4}$ Professor Convidado da Faculdade de Agronomia da Universidade Federal do Rio Grande do Sul - UFRGS, Bolsista 1 A do CNPq. Endereço Rua Largo Setembrina,126, Viamão - RS, CEP:94415-400. E-mail: ockoller@adufrgs.ufrgs.br 
deixaram de ser competitivos em custos ou qualidade. Diante deste cenário, surgiu o Programa de Fruticultura Irrigada da Metade Sul do Estado do Rio Grande do Sul, que tem como objetivo introduzir novas culturas na região, de forma a gerar empregos e a promover a circulação monetária.

Na metade sul do RS, a implantação de pomares e de quebraventos ainda se encontra em estágio inicial. O Estado está divido em diversos pólos frutícolas, sendo que o presente trabalho dedica-se apenas a estudar a comercialização dos produtos provenientes dos pomares implantados nos últimos seis anos, nos municípios de São Gabriel, Santa Margarida do Sul e Rosário do Sul.

Os citricultores da metade sul do RS pensavam, inicialmente, apenas na produção de frutas de qualidade, sem maior preocupação com o mercado. Estavam cientes de que havia mercado para as frutas sem sementes porque são diferenciadas e, em países europeus, já são amplamente consumidas. Dessa forma, os citricultores implantaram seus pomares objetivando exportar sua produção para a Europa, já que a produção no Rio Grande do Sul ocorre na entressafra européia. Porém, posteriormente, deramse conta de que, nos primeiros anos de colheita, não haveria volume nem fruta padronizada para exportar, passando então a repensar o seu mercado-alvo (Senna, 2003).

Assim sendo, este trabalho foi realizado com o intuito de verificar a existência de comerciantes na CEAGESP que já comercializam, ou que tenham interesse em comercializar frutas cítricas sem sementes e indagá-los quanto ao interesse em adquirir, futuramente, as frutas produzidas na metade sul do Rio Grande do Sul. Em suma, avaliou-se o mercado na CEAGESP com a finalidade de aproximar os produtores de seus possíveis compradores.

\section{MATERIAL E MÉTODOS}

A primeira etapa deste trabalho foi a escolha das abordagens teóricas que serviram como base para a construção do protocolo de entrevistas que foi aplicado junto aos comerciantes na CEAGESP e para a posterior análise das respostas.

Neste trabalho, foram utilizadas três abordagens teóricas para analisar o objeto de estudo: segmentação de mercado, gerenciamento da cadeia de suprimentos e canais de distribuição. A aplicação da abordagem de segmentação de mercado possibilita identificar as características, bem como a localização dos consumidores. $\mathrm{O}$ gerenciamento da cadeia de suprimentos permite avaliar e integrar os elos da cadeia produtiva e visualizar a dinâmica de fluxos de recursos, tecnologias, informações e produto, e, por fim, o foco é centralizado em canais de distribuição.

\section{Segmentação de Mercado}

Segundo Richers \& Lima (1991), o processo de segmentação de mercado caracteriza-se pela concentração consciente e planejada de uma empresa em parcelas específicas de seu mercado. A idéia central da segmentação é tirar proveito da desagregação da demanda ao concentrar os esforços de marketing em determinados focos que a empresa considera favoráveis para serem explorados comercialmente, porque acredita ter produtos capazes de satisfazer à demanda desses focos de maneira mais adequada do que seus concorrentes. Para Kotler (2000), um segmento de mercado consiste em um grande grupo que é identificado a partir de suas preferências, poder de compra, localização geográfica, atitudes e hábitos de compra similares.

Conforme Richers \& Lima (1991), podem-se classificar as modalidades de segmentos em categorias conceitualmente diferenciadas, tais como segmentação: geográfica, demográfica, socioeconômica, padrões de consumo, benefícios procurados, estilos de vida, personalidade e caracterização econômica.

\section{Gerenciamento da Cadeia de Suprimentos}

Cadeia de suprimento é todo esforço envolvido nos diferentes processos e atividades empresariais que criam valor nos produtos e serviços para o consumidor (Ching, 1999).

Wood \& Zuffo (1998) definem o gerenciamento da cadeia de suprimentos como uma metodologia desenvolvida para alinhar todas as atividades de produção de forma sincronizada, visando a reduzir custos, minimizar ciclos e maximizar o valor percebido pelo cliente final, por meio do rompimento das barreiras entre departamentos e áreas. Trata-se de uma metodologia empregada para promover o conceito de logística integrada, ou seja, desenvolver parcerias com fornecedores, melhorar as práticas adotadas durante a produção, revisão dos sistemas de distribuição e melhoria do sistema de informação.

\section{Canais de Distribuição}

Segundo Sproesser (1997), um canal de distribuição é constituído por um conjunto de agentes econômicos utilizados por uma empresa produtiva para difundir seus produtos junto aos consumidores. O canal é caracterizado principalmente por seu comprimento, ou seja, o número de agentes econômicos que o integram, e pela repartição das funções entre os agentes.

A diversidade do comportamento dos consumidores, as diversas situações de compra, as particularidades inerentes à distribuição de produtos alimentares e à organização dos canais, visando à otimização do processo de distribuição, justificam a existência de um número razoavelmente elevado de formas organizacionais de venda no varejo em livre serviço no Brasil. Seja qual for o canal de distribuição escolhido, os seus objetivos devem estar estreitamente vinculados às especificidades do produto ofertado e do público-alvo.

Devido ao volume ainda pequeno de frutas cítricas sem sementes, ofertado no mercado, e ao recente cultivo no País, pouco se sabe sobre as possibilidades de distribuição dessas frutas no Brasil. Assim, este trabalho tem como objetivo identificar os canais de distribuição que comercializam frutas cítricas de mesa sem sementes na cidade de São Paulo.

Realizou-se um estudo de caso de caráter exploratório, devido às características inerentes ao tema de pesquisa. A coleta de evidências foi realizada com dados primários obtidos através de entrevistas semi-estruturadas em profundidade, realizadas de acordo com um protocolo de entrevistas, sendo os depoimentos 
gravados em fita cassete e complementados com anotações feitas simultaneamente. Foram entrevistados comerciantes, localizados no Entreposto Terminal São Paulo (ETSP) da Companhia de Entrepostos e Armazéns Gerais de São Paulo (CEAGESP), selecionados da seguinte forma: para cada entrevistado, foi perguntado quem é o seu principal concorrente, e estes passou a ser o próximo entrevistado até chegar num momento em que todos os comerciantes que trabalhavam com citros sem sementes na CEAGESP, foram entrevistados, num total de dez. O protocolo de entrevistas foi dividido em grupos, da seguinte forma: no grupo 1 , as questões estão direcionadas para segmentação de mercado e comercialização; no grupo 2, visam ao esclarecimento da comercialização, gerenciamento da cadeia de suprimentos e canais de distribuição, e no grupo 3, relacionam-se à segmentação de mercado e canais de distribuição.

O primeiro passo após a coleta de dados foi a transcrição de depoimentos anotados e gravados. A seguir, passou-se para a análise dos resultados, com o propósito de contar a freqüência de um fenômeno e identificar relações entre fenômenos, sendo que a interpretação dos dados é apoiada nos modelos conceituais definidos no referencial teórico (Roesch, 1996).

Como se trata de uma pesquisa de caráter qualitativo, a avaliação dos dados foi realizada através da análise descritiva dos dados coletados, visando à ligação com as abordagens teóricas utilizadas no desenvolvimento da pesquisa. A análise dos resultados foi feita da seguinte maneira: primeiro, prepararamse as informações (reuniu-se o material necessário para análise); depois, classificou-se o material em categorias (agruparam-se os dados classificando-os por semelhança ou analogia); a seguir, fez-se a descrição (relataram-se os resultados da pesquisa), e, por último, interpretaram-se os dados.

\section{RESULTADOS E DISCUSSÃO}

Entrevistaram-se, no Entreposto Terminal São Paulo (ETSP) da Companhia de Entrepostos e Armazéns Gerais de São Paulo (CEAGESP), dez estabelecimentos comerciais, sendo que destes, seis são atacadistas; três são empresas importadoras, exportadoras e distribuidoras de frutas no mercado interno, e uma loja é especializada, conforme ilustra a Figura 1. Desses, seis já comercializaram ou continuam comercializando frutas cítricas sem sementes e quatro empresas não comercializam frutas cítricas sem sementes, mas têm interesse em comercializá-las futuramente, por isso essas empresas também responderam a todas as perguntas, totalizando dez respostas para cada item.

Lojas especializadas são pontos de venda no varejo, onde se comercializam produtos importados, de excelente qualidade, para atender um público-alvo exigente, de alto poder aquisitivo.

Constatou-se que uma empresa importa frutas cítricas sem sementes do Uruguai e da Espanha (Empresa 3) e distribuias para outras empresas (Empresas 1 e 2, Loja Especializada 1, Atacadista 1 e Supermercados) que as redistribuem para outros canais, como ilustrado na Figura 1. Quando foram realizadas as entrevistas, em setembro de 2002, todas as frutas cítricas sem sementes, encontradas na CEAGESP, eram provenientes do Uruguai.
Os comerciantes da CEAGESP manifestaram maior interesse por tangerinas do que por laranjas, mas preferiram não apontar variedades. Quanto aos comerciantes que trabalham com frutas cítricas sem sementes, quatro destacaram as laranjas-deumbigo e as cultivares de tangerinas Ellendale, Salteñita (Montenegrina), Clementina, Ortanique e Okitsu (Quadro 1).

Os dez comerciantes não exigem do fornecedor o pagamento de taxas para cadastramento ou para iniciar a negociação. Quanto ao procedimento de negociação, segundo os comerciantes, segue-se a seguinte seqüência: primeiro o produtor deve fazer contato via telefone para ofertar as frutas e verificar se há interesse do comerciante em adquirir o produto e, posteriormente, faz um cadastro via fax, telefone ou pessoalmente. Um comerciante manifestou a intenção de visitar os pomares antes de concretizar a transação.

Indagados sobre as épocas mais propícias para o fornecimento das frutas sem sementes, os comerciantes informaram que, havendo oferta, os citros podem ser comercializados o ano inteiro. Entretanto, segundo a maioria dos entrevistados, a partir de setembro, faltam tangerinas no mercado, levando os comerciantes a importarem frutas do Uruguai, de outubro a dezembro, e da Espanha, em janeiro e fevereiro. Somente uma empresa importadora realiza a importação destes países; os demais entrevistados que trabalham com frutas cítricas neste período, adquirem-nas dessa empresa. De março a junho, é o período em que as frutas cítricas brasileiras são ofertadas em maior quantidade e com melhor qualidade.

Os comerciantes entrevistados na CEAGESP responderam que pagam seus fornecedores respeitando os seguintes prazos:

1-Oito comerciantes pagam de 30 a 60 dias após o recebimento da mercadoria.

2-Um respondeu que o prazo depende muito da negociação com o fornecedor.

3-Um respondeu que não está comprando hoje frutas de terceiros.

Em geral, as empresas pagam seus fornecedores a prazo. Seis entrevistados disseram que o produtor precisa levar as frutas até a CEAGESP. Três opinaram que depende muito da negociação, da qualidade das frutas e da distância do local da produção, e um disse que busca as frutas na propriedade localizada no interior paulista.

Para oito comerciantes, é mais vantajoso negociar cargas com várias espécies de frutas, tanto para fechar a carga, quanto para facilitar a negociação, para ambas as partes, podendo até aumentar a freqüência da negociação. Para outros dois, tanto faz, não muda em nada a negociação.

Outro tema tratado foi o tipo de embalagem com a qual a fruta é comercializada. Quatro comerciantes responderam que embalam em bandejas com poucas frutas ou ensacam em embalagens pequenas, adicionando a marca da rede, ou ainda uma terceira marca. Este é o caso de uma empresa importadora e exportadora que embala também em sacos pequenos com a marca Xuxa, mas também com a marca própria. Cinco comerciantes comercializam nas caixas fornecidas pelo produtor e um disse que depende da fruta. Frutas mais valorizadas, que possuem um preço mais alto, são embaladas geralmente em bandejas ou caixas de 
papelão.

Nos estabelecimentos entrevistados na CEAGESP, apenas em três havia frutas com a marca do produtor; quatro consideram opcional, dependendo do produtor, não diferenciando em nada a negociação; dois afirmaram que seus produtos são distribuídos com a marca da rede, e um disse que depende muito do acerto entre as partes, mas, em muitos casos, as frutas acabam sendo identificadas com as duas marcas: a da rede e a do produtor.

Dos fornecedores dos comerciantes da CEAGESP, cinco pagam o transporte das frutas do pomar até a empresa. Já para dois, é na negociação que se determina quem pagará o transporte. Três responderam que pagam o transporte, mas destes apenas um assumiu que o valor do transporte é descontado posteriormente do pagamento da mercadoria. Nesse caso, o produtor teria a vantagem de não precisar desembolsar o valor do transporte antes de receber o valor da venda das frutas. No caso da importação de tangerinas, o frete das frutas é determinado na negociação, se a condição será CIF ou FOB.

Dos comerciantes de São Paulo, seis responderam que as perdas por perecibilidade dependem das condições em que as frutas saem do pomar: se a fruta for colhida no ponto certo e adequadamente, as perdas tenderão a zero.

Para a maioria dos entrevistados na CEAGESP, os principais atributos decisórios no processo de compra são: em primeiro lugar, a boa aparência (nove entrevistados) e, em segundo, o sabor (quatro entrevistados).

Os comerciantes entrevistados consideram que seus concorrentes estão presentes na CEAGESP.

Verificou-se, pois, que na cidade de São Paulo existe mercado para frutas cítricas sem sementes, cujo suprimento está sendo realizado através de importações do Uruguai e da Espanha. Dados do Brasil (2007), especificam que, no ano de 2002, em que

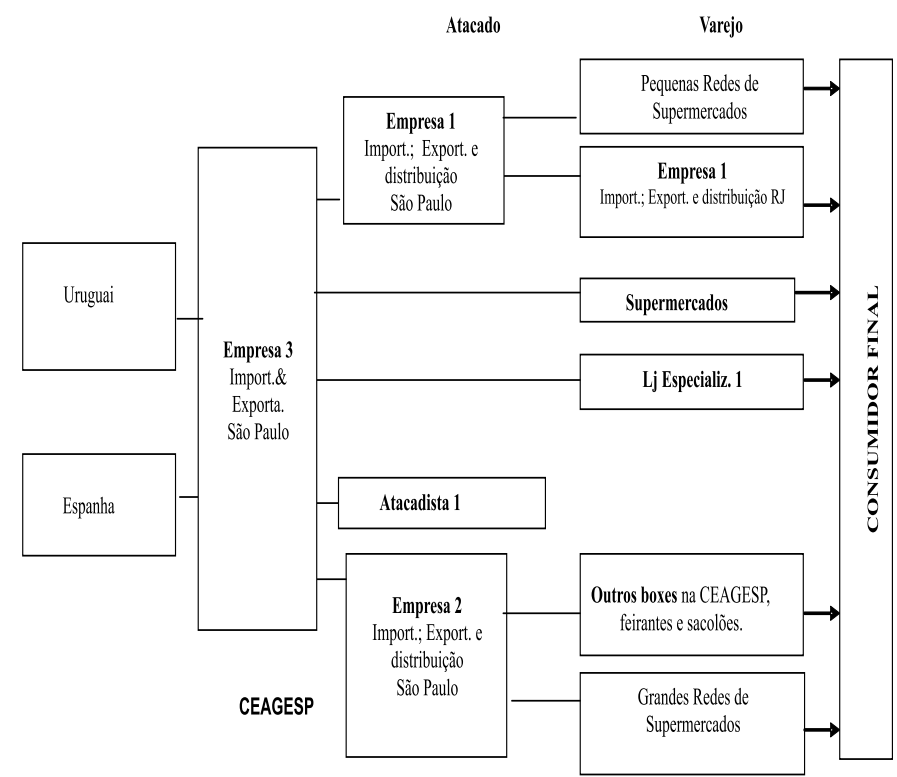

FIGURA 1 - Cadeia de distribuição das frutas cítricas sem sementes, provenientes do Uruguai e da Espanha, na cidade de São Paulo foram realizadas as entrevistas na CEAGESP, a quantidade de frutas cítricas importada do Uruguai foi de 2.064 toneladas e, da Espanha, cerca de 700 toneladas (Quadro 2). Em 2006, a quantidade de frutas cítricas importada da Espanha foi de 907 toneladas, enquanto do Uruguai foram importadas 1.165 toneladas. O valor pago pelos citros importados da Espanha foi de US\$ $776,81 /$ tonelada, em 2006, mais que o dobro do valor pago pela fruta importada do Uruguai, que foi de US\$305,62/tonelada.

Enfim, como na metade sul do Rio Grande do Sul diversos pomares ainda estão em fase de implantação e início de produção de frutas sem sementes, é necessário que haja desde já um estreitamento entre os elos da cadeia produtiva, para que se direcione a produção para abastecer os comerciantes que já trabalham com esse tipo de fruta, porém importam-na de outros países. Neste trabalho, identificou-se a rota das frutas cítricas sem sementes comercializadas na CEAGESP e quais os procedimentos e as condições para se negociar com esses comerciantes. Os citros sem sementes são frutas diferenciadas que, se comercializadas na CEAGESP, são isentas da cobrança das taxas e bonificações das redes de supermercados e também se evitam despesas na divulgação do produto.

TABELA 1 - Síntese das informações obtidas nas entrevistas na CEAGESP.

\begin{tabular}{|c|c|}
\hline $\begin{array}{c}\text { Questões abordadas nas } \\
\text { entrevistas }\end{array}$ & Comerciantes de São Paulo \\
\hline $\begin{array}{l}\text { Perfil das empresas de } \\
\text { distribuição em São Paulo }\end{array}$ & $\begin{array}{c}6 \text { atacadistas; } 3 \text { importadoras, } \\
\text { exportadoras e distribuidoras de } \\
\text { frutas no mercado interno, e } 1 \text { loja } \\
\text { especializada }\end{array}$ \\
\hline $\begin{array}{l}\text { Comercializam citros sem } \\
\text { sementes }\end{array}$ & 6 comerciantes da Ceagesp \\
\hline Preferência por variedades & $\begin{array}{l}\text { Comuns: tangerinas foram } \\
\text { preferidas } \\
\text { Sem sementes: Laranjas-de- } \\
\text { Umbigo e Tangerinas: Ellendale, } \\
\text { Salteñita, Ortanique e Okitsu }\end{array}$ \\
\hline Existem taxas para negociar & $\begin{array}{l}10 \text { comerciantes disseram que não } \\
\text { cobram taxas }\end{array}$ \\
\hline Procedimento para negociar & $\begin{array}{c}1^{\circ} \text { contato via telefone e } 2^{\circ} \text { faz-se } \\
\text { cadastro por fax, telefone ou } \\
\text { pessoalmente }\end{array}$ \\
\hline $\begin{array}{l}\text { Épocas propícias para } \\
\text { fornecimento }\end{array}$ & $\begin{array}{l}10 \text { entrevistados comercializam } \\
\text { frutas cítricas o ano inteiro }\end{array}$ \\
\hline $\begin{array}{c}\text { Forma de pagamento ao } \\
\text { fornecedor }\end{array}$ & $\begin{array}{c}\text { Prazo de } 30 \text { a } 60 \text { dias após a } \\
\text { entrega ( } 8 \text { comerciantes })\end{array}$ \\
\hline $\begin{array}{l}\text { Demandam embalagens com } \\
\text { poucas frutas }\end{array}$ & $\begin{array}{l}9 \text { comerciantes recebem frutas em } \\
\text { caixas de papelão ou madeira }\end{array}$ \\
\hline $\begin{array}{c}\text { Responsabilidades do produtor } \\
\text { e empresa }\end{array}$ & $\begin{array}{c}\text { O produtor deve entregar as frutas } \\
\text { na CEAGESP ( } 6 \text { comerciantes) }\end{array}$ \\
\hline $\begin{array}{c}\text { É melhor negociar frutas de } \\
\text { outras espécies }\end{array}$ & $\begin{array}{c}\text { É mais vantajoso que a } \\
\text { negociação envolva outras frutas } \\
\text { (8 comerciantes) }\end{array}$ \\
\hline $\begin{array}{l}\text { Produtor pode comercializar } \\
\text { com marca própria }\end{array}$ & $\begin{array}{l}\text { Para } 7 \text { comerciantes, o produtor } \\
\text { pode comercializar com marca } \\
\text { própria (procedimento normal) }\end{array}$ \\
\hline Perdas nos canais & $\begin{array}{l}\text { Dependem das condições em que } \\
\text { as frutas saem do pomar e do } \\
\text { ponto de colheita ( } 6 \text { comerciantes) }\end{array}$ \\
\hline $\begin{array}{c}\text { Atributos procurados nas frutas } \\
\text { cítricas }\end{array}$ & $\begin{array}{c}1^{\circ} \text { aparência }(9 \text { comerciantes }) \text { e } 2^{\circ} \\
\text { sabor }(4 \text { comerciantes })\end{array}$ \\
\hline Localização dos consumidores & $\begin{array}{c}\text { São Paulo (4 comerciantes) } \\
\text { localizaram seus consumidores, } 6 \\
\text { comerciantes forneceram } \\
\text { respostas variadas }\end{array}$ \\
\hline
\end{tabular}

Fonte: Dados coletados. 
TABELA 2 - Frutas cítricas importadas do Uruguai e da Espanha, pelo Brasil, em toneladas, dólares e dólares por tonelada, no período compreendido entre janeiro de 2000 e dezembro de 2006.

\begin{tabular}{|c|c|c|c|c|c|c|}
\hline Ano & \multicolumn{3}{|c|}{ Uruguai } & \multicolumn{3}{|c|}{ Espanha } \\
\cline { 2 - 7 } & Vol (t) & US\$ & US\$/t & Vol (t) & US\$ & US\$/t \\
\hline 2000 & 1.095 & $369.322,00$ & 337,28 & 1.206 & $662.606,00$ & 549,42 \\
\hline 2001 & 1.083 & $291.603,00$ & 269,25 & 493 & $274.558,00$ & 556,91 \\
\hline 2002 & 2.064 & $369.717,00$ & 179,13 & 699 & $395.615,00$ & 565,97 \\
\hline 2003 & 1.270 & $291.717,00$ & 229,70 & 328 & $217.938,00$ & 664,45 \\
\hline 2004 & 936 & $209.990,00$ & 224,35 & 164 & $114.588,00$ & 698,71 \\
\hline 2005 & 3.613 & $860.421,00$ & 238,15 & 473 & $357.548,00$ & 755,92 \\
\hline 2006 & 1.165 & $356.043,00$ & 305,62 & 907 & $704.569,00$ & 776,81 \\
\hline
\end{tabular}

Fonte: Ministério do Desenvolvimento, Indústria e Comércio.

\section{CONCLUSÕES}

1- As frutas cítricas sem sementes (exceção às laranjasde-umbigo e limão Tahiti) ainda são pouco cultivadas, pouco conhecidas e, conseqüentemente, pouco comercializadas no Brasil.

2- Na cidade de São Paulo, há mercado para frutas cítricas sem sementes, que está sendo atendido de maneira eficaz por frutas provenientes do Uruguai, na mesma época de colheita das frutas produzidas na metade sul do Rio Grande do Sul. Para que estas conquistem seu espaço, os produtores devem investir na boa qualidade das frutas e na melhoria da organização comercial.

3- Nos primeiros anos de produção é mais conveniente que os produtores comercializem os frutos com os comerciantes que já trabalham com variedades de frutas cítricas sem sementes, porém, na medida em que estes forem atendidos e houver um volume maior de frutas, outros canais de distribuição podem ser incorporados, conseqüentemente aumentará o poder de barganha do produtor na negociação.

\section{REFERÊNCIAS}

BOTEON, M. Mercado interno de frutas cítricas. 2000. $86 \mathrm{f}$. Dissertação (Mestrado) - Escola Superior de Agricultura "Luís de Queiroz", Universidade de São Paulo, Piracicaba, 2000.

BRASIL-MINISTÉRIO DODESENVOLVIMENTO, INDÚSTRIA E COMÉRCIO EXTERIOR. Dados de importação de frutas cítricas, compreendidos entre 1996 e 2006. Disponível em: < http:// www.desenvolvimento.gov.br>. Acesso em: 1 mar. 2007.

CHING, H.Y. Gestão de estoques na cadeia de logística integrada: supply chain. São Paulo: Atlas, 1999. p. 55-82.

KOTLER, P. Administração de marketing: a edição do novo milênio. São Paulo: Prentice Hall, 2000. 768 p.

RICHERS, R.; LIMA, C. P. Segmentação: opções estratégicas para o mercado brasileiro. São Paulo: Nobel, 1991. 304 p.
ROESCH, S.M.A. Projetos de estágio do curso de administração: guia para pesquisas, projetos, estágios e trabalhos de conclusão de curso. São Paulo: Atlas, 1996. 307 p.

SENNA, A.J. Configuração da cadeia de distribuição de frutas cítricas, de mesa, sem sementes, nas regiões Sul e Sudeste. 2003. 178 f. Dissertação (Mestrado em Agronegócios) Universidade Federal do Rio Grande do Sul, Porto Alegre, 2003.

SPROESSER, R.L. Gestão estratégica do comércio varejista. In: BATALHA, M.O. (Org.). Gestão agroindustrial. São Paulo: Atlas, 1997. v.1, p 215-261.

WOOD JR., T.; ZUFFO, P.K. Gerenciamento da cadeia de suprimentos. Revista de Administração de Empresas, São Paulo, v.38, n.3, p.55-63, 1998. 